Paper

\title{
Wavy Micro Channels in Micropatterned Ceramic Sheet Formed by Combined Process of Laser Beam Machining and Imprinting
}

\author{
Fujio TSUMORI ${ }^{1}$, Simon HUNT $^{2}$, Kentaro KUDO ${ }^{2}$, Toshiko OSADA ${ }^{1}$ and Hideshi MIURA ${ }^{1}$ \\ ${ }^{1}$ Department of Mechanical Engineering, Kyushu University, 744 Motooka, Nishi-ku, Fukuoka 819-0395, Japan. \\ ${ }^{2}$ Graduate School of Engineering, Department of Mechanical Engineering, Kyushu University, 744 Motooka, Nishi-ku, Fukuoka 819-0395, Japan.
}

Received November 30, 2015; Revised January 7, 2016; Accepted February 12, 2016

\begin{abstract}
Micro channels made of polymers are commonly used for MEMS and $\mu$ TAS (micro-total analysis system) devices. In this research, we developed a process for fabricating a ceramic sheet with micro channels. The developed process is based on powder metallurgy process. A compound material, a mixture of ceramic powder and polymer, was prepared as sheet material. We employed laser machining to machine the sacrificial layer to form micro channels inside the sheet. We also employed imprinting, which is a process of pressing with a mould while heating, to form a structure with surface patterns and micro channels curving along with it. After the imprinted sheet was debound and sintered by heating, a ceramic sheet with micro-surface patterns and micro channels was obtained. As ceramics have high heat durability and low chemical reactivity, ceramic micro channels can be used for flow sensors or chemical reaction testers operated in harsh environments, such as high temperature or mechanical parts operated with reactive chemicals. In addition, by imprinting wavy patterns, the surface area can be increased. Therefore high efficiency heat exchangers can be built. Moreover, this method can be applied on SOFCs (solid oxide fuel cell) by fabricating YSZ (yttria stabilized zirconia) micro channels.
\end{abstract}

\section{KEY WORDS}

micro channels, imprinting, laser beam machining, ceramic

\section{Introduction}

Micro channels formed of polymer materials are commonly used for chemical reaction testers or MEMS (Micro Electro Mechanical Systems). The use of micro channels helps downsizing these devices as well as increasing the operating efficiency. Several fabrication processes for polymer micro channels have been reported ${ }^{1-5)}$.

In this paper, we propose a fabrication method for ceramic micro channels. Since ceramic materials have low chemical reactivity and high heat durability, ceramic micro channels can be applied for chemical reaction testers or MEMS used in harsh environments. In addition, as our microchannel fabrication method enables surface patterning, micro channels with large surface area can be obtained. Therefore high efficiency heat exchangers can be built. Moreover, by using YSZ (yttria stabilized zirconia) as structure material, this microchannel forming method can be applied on SOFCs (Solid Oxide Fuel Cells).

In the process of forming ceramic micro channels, micro powder imprinting method, which has been developed by our group ${ }^{6-13)}$, was employed in order to fabricate alumina compound sheets

* Corresponding author, E-mail: tsumori@mech.kyushu-u.ac.jp with surface patterns. The micro powder imprinting method has been proposed to enable micro patterning on the surface of ceramic sheets. Micro patterned ceramic sheets can effectively improve the performance of solid oxide fuel cells ${ }^{14-17)}$. This method combines powder metallurgy $(\mathrm{P} / \mathrm{M})$ process and nanoimprinting lithography ${ }^{18-22)}$, which is an approach to transfer fine patterns to plastic polymer materials by using patterned moulds. The authors focused on powder processing. A compound material which is a mixture of powder material and polymer can be thermally imprinted. After removing the polymer by heat and sintering, the powder material consolidates, and a dense inorganic structure is obtained. This process can be applied on any material suitable for the powder metallurgy process.

We also employed laser beam machining in order to form micro channels. Laser beam machining removes material by melting or by direct vaporization and ablation. It is non-contact machining and inflicts almost negligible force to the machined object, which enables machining of delicate objects. In addition, it can remove material at atomic level. This allows micro machining.

Our micro channel forming process combines laser beam machining, a technique of interposing laser beam machined sacrificial layers, 
and imprinting. In our previous work $^{23)}$ we were successful at forming micro channels with micro patterns. In this work we have carried out thermal analysis on alumina compound sheets in order to find the optimum imprinting temperature. In addition, we attempted on forming micro channels curving along surface patterns by using a deep mould during the imprinting process.

\section{Materials}

In order to fabricate alumina compound sheets, poly(vinyl alcohol) (Wako Pure Chemical Industries. Ltd., polymerization degree: 500, $T_{\mathrm{m}}: 194^{\circ} \mathrm{C}$ ), glycerin (Wako Pure Chemical Industries.Ltd.) and alumina powder (TM-DAR, Taimei Chemicals Co. Ltd., particle diameter: $0.10 \mu \mathrm{m})$ were prepared. We also prepared polyimide (Upilex-25RN, Ube Industries, Ltd.) as middle layer material.

We carried out thermal analysis of alumina compound sheets, as fluidity of alumina compound sheets at different imprinting temperatures and decomposition temperatures of polymers included in the alumina compound sheet are important elements in our work.

The DSC (Differential Scanning Calorimetry) curve of alumina compound sheet [50 vol\% alumina, 35 vol\% poly(vinyl alcohol) and $15 \mathrm{vol} \%$ glycerin], which was conducted in $\mathrm{N}_{2}$ atmosphere at a heating rate of $10{ }^{\circ} \mathrm{C} / \mathrm{min}$, is shown in Fig. 1. From this curve, we can see that the $T_{m}$ (melting temperature) of PVA included in the alumina compound sheet decreased to $119^{\circ} \mathrm{C}$ due to the influence of glycerin working as plasticizer. TGA (Thermogravimetric analysis) was also carried out in air flow at a heating rate of $10^{\circ} \mathrm{C} / \mathrm{min}$ As shown in Fig. 2, there were three reduction peaks. The first peak is the decomposition of glycerin, which is decomposed entirely at $200{ }^{\circ} \mathrm{C}$. The following two peaks indicate PVA decomposing in two stages at $270{ }^{\circ} \mathrm{C}$ and at $450{ }^{\circ} \mathrm{C}$.

\section{Fabrication procedure}

The fabrication of alumina micro channels is carried out through 4 processes. The outline of the whole procedure is described in Fig. 3. At first, an alumina compound sheet with a resin layer on top is prepared (Fig. 3a). Next, the resin layer is laser beam machined into the shape of micro channels (Fig. 3b). After this, an alumina compound sheet is added on top of the laser beam machined resin layer. A mould is placed on top of this stack, and the imprinting process is carried out (Fig. 3c). During the imprinting process, the upper and lower layer alumina compound sheets push through gaps, which were formed by laser beam machining prior to this process, and the stack is fabricated into a single sheet with surface patterns and a resin layer in the middle (Fig. 3d). Finally, the imprinted sheet is put into a furnace for debinding, which is a process for decomposing, which is a process for eliminating polymer within the alumina compound sheet, and sintering. After the whole process, a wavy patterned alumina sheet with micro channels are obtained.

The details of each process are indicated in the following sections;

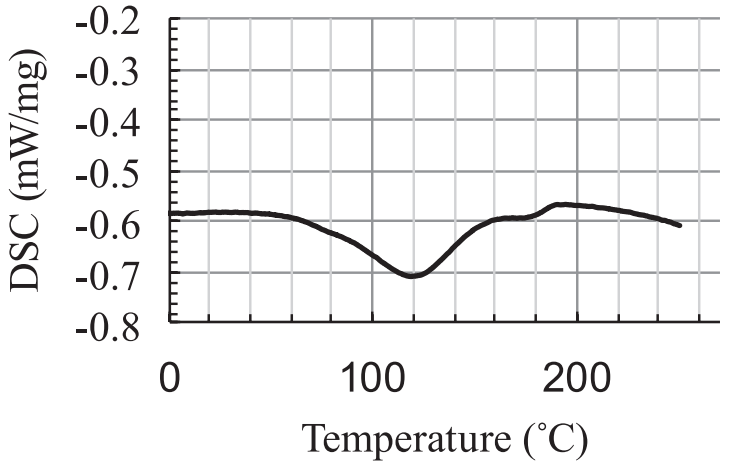

Fig. 1 Differential Scanning Calorimetry of 50 vol $\%$ alumina compound sheet

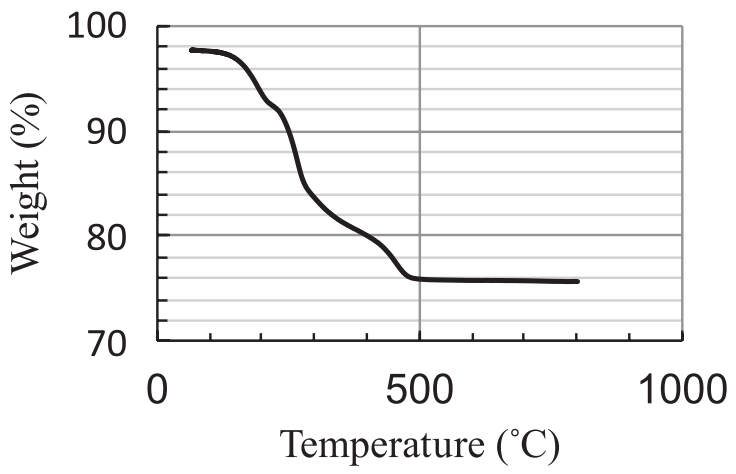

Fig. 2 Thermogravimetric Analysis of 50 vol\% alumina compound sheet.

sect. 3.1 for the preparation of alumina compound sheets, sect. 3.2 for laser beam machining, sect. 3.3 for imprinting and sect. 3.4 for debinding and sintering.

3.1 Preparation of alumina compound sheets

The alumina compound sheets are prepared by sheet casting a mixture of alumina powder, binder [poly(vinyl alcohol)], plasticizer (glycerin) and water. The composition was homogenously dispersed by ultrasonic treatment, and then sheet casted to form thin uniform sheets using a table coater (Mitsui Electric, TC-1). The sheets were then placed into an oven and heated at a temperature of $80^{\circ} \mathrm{C}$ for 15 minutes to dry out. The thickness of alumina compound sheets were set at $70 \mu \mathrm{m}$, since on attempts of forming thicker sheets, uniformity was compromised.

Three kinds of alumina compound sheets with compounding ratios as indicated in Table 1 were prepared for our experiment. The compounding ratio of alumina was $55 \mathrm{vol} \%, 50 \mathrm{vol} \%$ and $45 \mathrm{vol} \%$. This is an important factor for the following imprinting process and debinding process. Less alumina powder allows better formability during the imprinting process, however, it causes larger shrinkage, which could lead to cracks or deformation during the debinding process.

3.2 Laser beam machining

Laser beam machining was employed in order to process middle layer resin into the shape of micro channels. A diagram of the laser beam machining apparatus is shown in Fig. 4. The laser beam is discharged from the laser oscillator (Q-switch DPSS laser, LVE-G0300, 


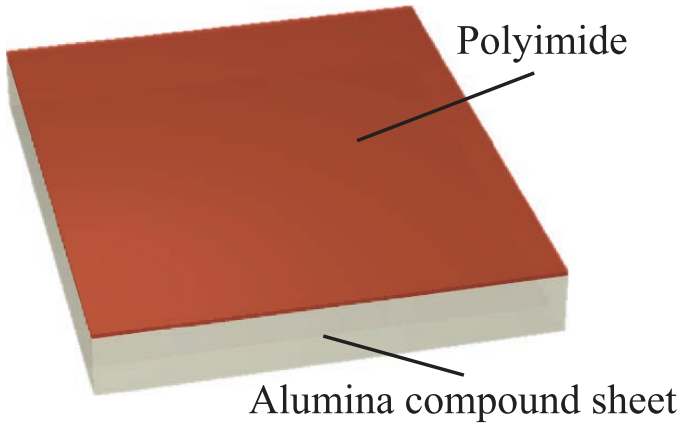

(a)

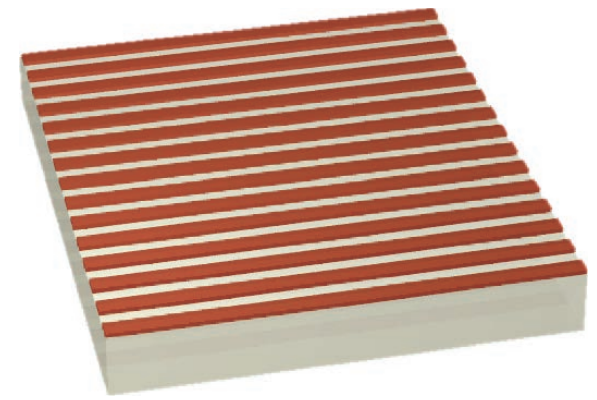

(b)

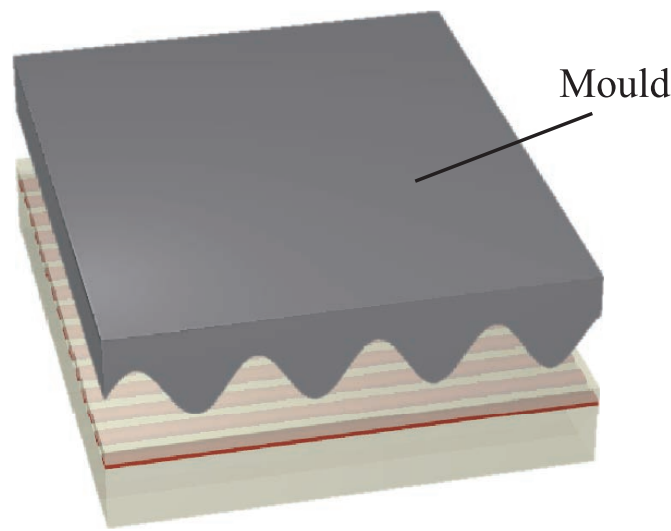

(c)

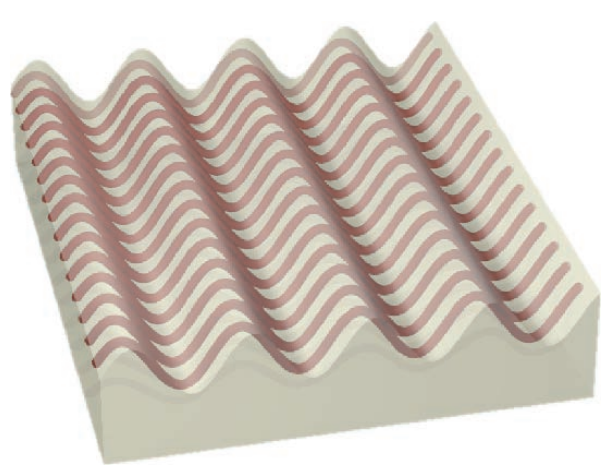

(d)

Fig. 3 Outline of micro channel forming process.

Spectronix Co.), and is guided through the beam expander and the attenuator, which controls the output power. Next, the laser beam enters the Galvano mirror, which controls the path of the laser beam according to the machining program prepared on a computer. Finally, the laser beam is converged by the F-theta-lens and the object on the substrate is laser beam machined. The speculation of the laser oscillator is shown in Table 2. Wave length of the laser beam is $532 \mathrm{~nm}$, and the spot diameter is $9.6 \mu \mathrm{m}$.

Polyimide with a thickness of $25 \mu \mathrm{m}$ was prepared as middle layer resin, as its optical and mechanical properties are suitable for laser beam machining and imprinting. A simple line-and-space pattern with a width of $50 \mu \mathrm{m}$ and a pitch of $150 \mu \mathrm{m}$ as shown in Fig. $3 \mathrm{~b}$ was machined in this research. The laser power was set at $650 \mathrm{~mW}$, the pulse frequency was $200 \mathrm{kHz}$ and the pattern was machined 8 times in order to achieve fine machined samples.

\subsection{Imprinting}

Alumina compound sheets and laser beam machined polyimide were stacked up as shown in Fig. 5 before imprinting. As our sheet casting method only allows fabrication of alumina compound sheets with a thickness of up to $70 \mu \mathrm{m}$, we piled up several alumina compound sheets in order to achieve sufficient thickness. Six alumina compound sheets were piled up as lower layer, a laser beam machined polyimide layer was placed above and two more alumina compound sheets were added on top of the polyimide layer. This stack was first laminated by heating at $40{ }^{\circ} \mathrm{C}$ and compressed to form a $450 \mu \mathrm{m}$ sheet. Next, a steel mould was placed on top for the imprinting process. The mould, which has a depth of $300 \mu \mathrm{m}$ and a pitch of $600 \mu \mathrm{m}$ is shown in Fig. 6. It was prepared by wire electric discharge machining. Imprinting depth was set at $350 \mu \mathrm{m}$ and the imprinting temperature was altered.

Heating is a key factor of the imprinting process. Imprinting temperature is commonly set at temperatures where the fluidity of the polymer being imprinted is sufficient to form surface patterns without cracks. The imprinting conditions were set, taking the DSC curves obtained earlier into account. The imprinting temperatures were selected at $40^{\circ} \mathrm{C}$ which is before the melting starts, $70{ }^{\circ} \mathrm{C}$ where the melting starts, $100{ }^{\circ} \mathrm{C}$ which is in the middle of the melting process and $130{ }^{\circ} \mathrm{C}$ which is passed the peak of the melting process for alumina compound sheets with alumina compounding ratios of $45 \mathrm{vol} \%, 50 \mathrm{vol} \%$ and $55 \mathrm{vol} \%$.

\subsection{Debinding and sintering}

After Imprinting, the stack was placed into an oven for debinding and sintering. Taking the TGA result into account, the debinding and sintering process was executed according to the timetable of Fig. 7. First, the oven is heated up to $200{ }^{\circ} \mathrm{C}$ and kept for $7.2 \mathrm{ks}(2 \mathrm{~h})$ for the glycerin to decompose. Next, the temperature is increased to $270{ }^{\circ} \mathrm{C}$ and held for $2 \mathrm{~h}$. After this, the temperature is raised and held at $450{ }^{\circ} \mathrm{C}$ for $2 \mathrm{~h}$. At this point, the polymers included in the alumina compound sheet are expected to be fully decomposed. Next, the oven is heated up to, and kept at $1350{ }^{\circ} \mathrm{C}$ for $2 \mathrm{~h}$ for the sintering process. During this, the polyimide strips decompose, the alumina powder consolidates, and a dense alumina structure with micro channels is formed. 
Table 1 Composition of alumina compound sheets.

\begin{tabular}{ccc}
\hline Alumina $($ vol $\%)$ & Poly(vinyl alcohol) $($ vol $\%)$ & Glycerin $($ vol $\%)$ \\
\hline 55 & 31.5 & 13.5 \\
50 & 35 & 15 \\
45 & 38.5 & 16.5 \\
\hline
\end{tabular}

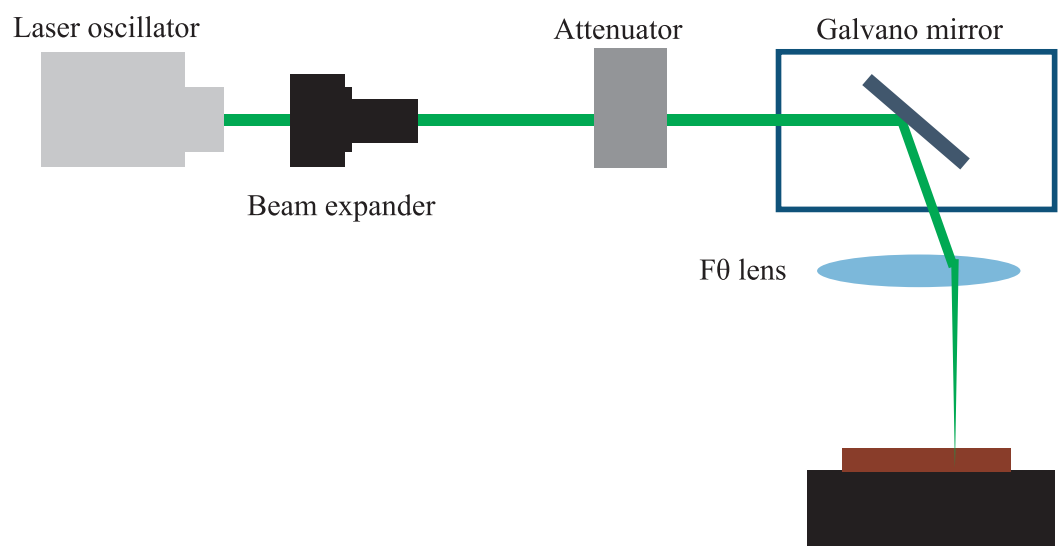

Fig. 4 Schematic of laser beam machining apparatus.

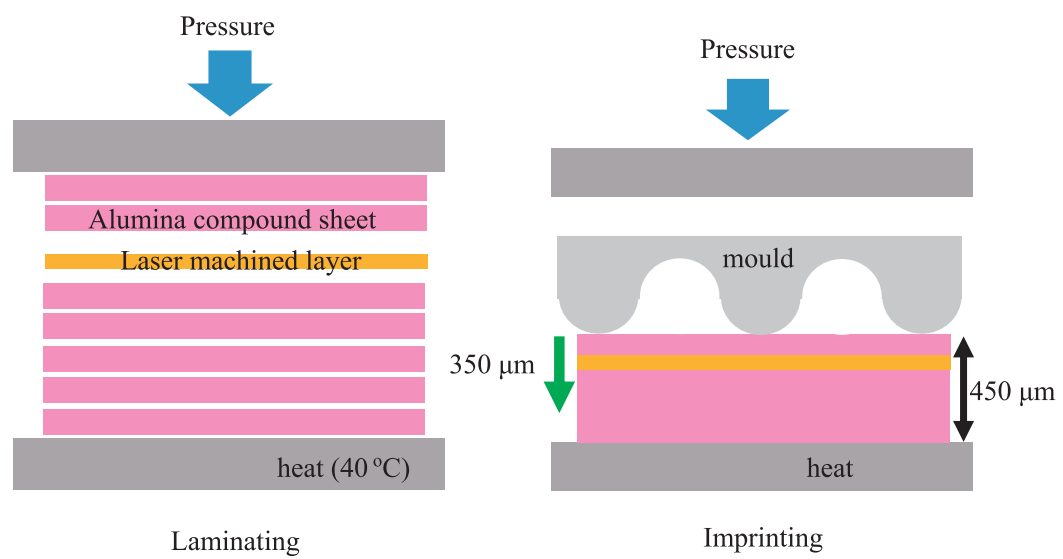

Fig. 5 Experimental setup for laminating and imprinting.

Table 2 Speculation of laser oscillator.

\begin{tabular}{cc}
\hline Wave length & $532 \mathrm{~nm}$ \\
Output & $3 \mathrm{~W}$ at $50 \mathrm{kHz}$ \\
Repetitive frequency & Max $200 \mathrm{kHz}$ \\
Pulse energy & $70 \mu \mathrm{J}$ at $50 \mathrm{kHz}$ \\
Pulse width & $15 \mathrm{~ns}$ at $50 \mathrm{kHz}$ \\
Spot diameter & $9.6 \mu \mathrm{m}$ \\
\hline
\end{tabular}
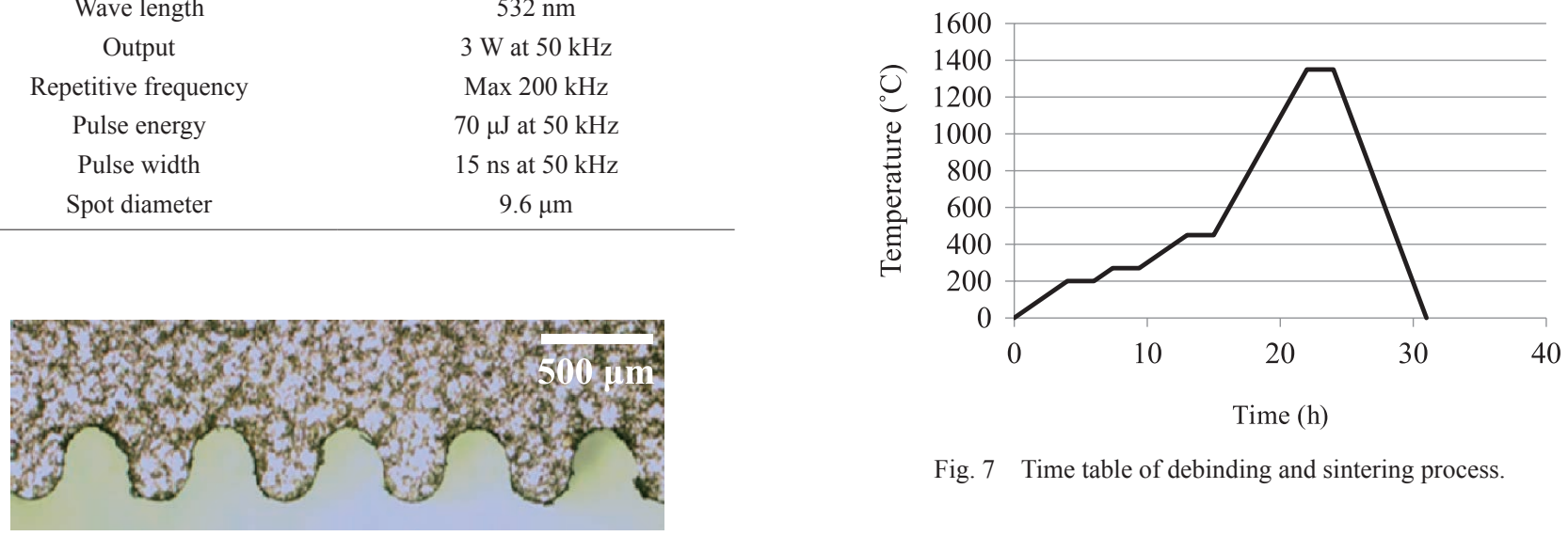

Fig. 7 Time table of debinding and sintering process.

Fig. 6 Mould with a depth of $300 \mu \mathrm{m}$ and a pitch of $600 \mu \mathrm{m}$. 


\section{Results and discussion}

4.1 Laser beam machining

Laser beam machining of the middle layer polyimide was carried out at a relatively low output power of $650 \mathrm{~mW}$ for 8 scans. The laser beam machined polyimide is shown in Fig. 8. By carrying out the laser beam machining process at low output power for several scans, the machined surface was smoother than that obtained with higher output power for fewer scans.

Since the width of the machined polyimide determines the width of the micro channels, the reduction of pitch will enable fabrication of smaller micro channels. With the present laser beam machining apparatus, we have succeeded in forming $50 \mu \mathrm{m}$ channels. By reducing the spot diameter of the laser beam, smaller micro channels can be formed.

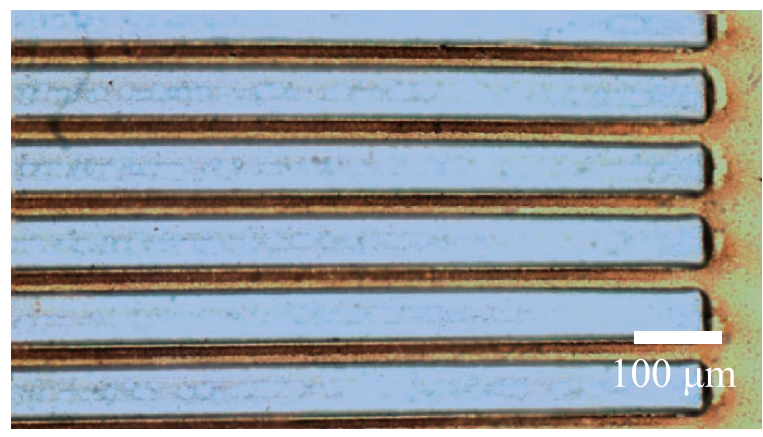

Fig. 8 Laser beam machined middle layer polyimide.
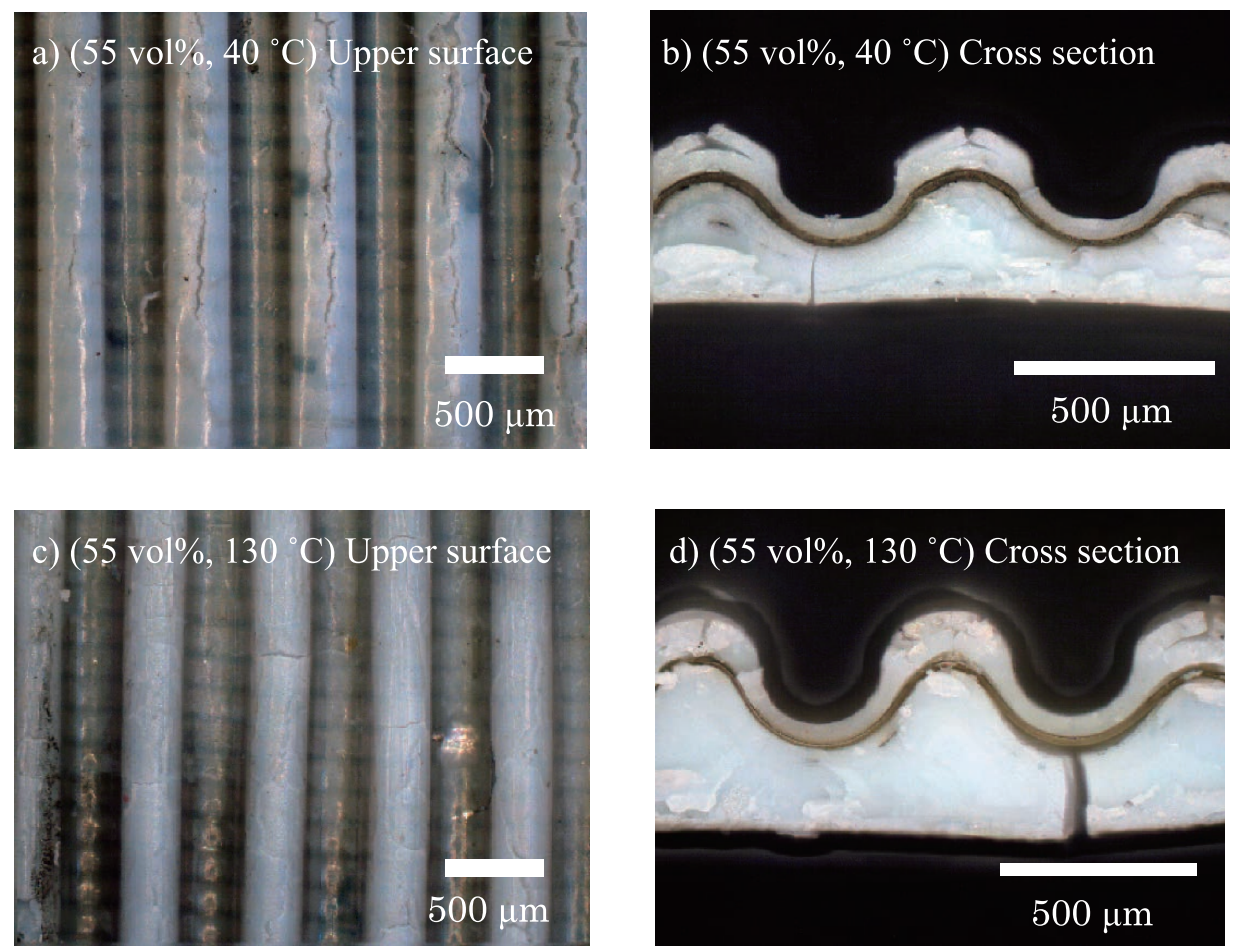

Fig. 9 Optical images of imprinted 55 vol\% alumina compound sheet samples. 

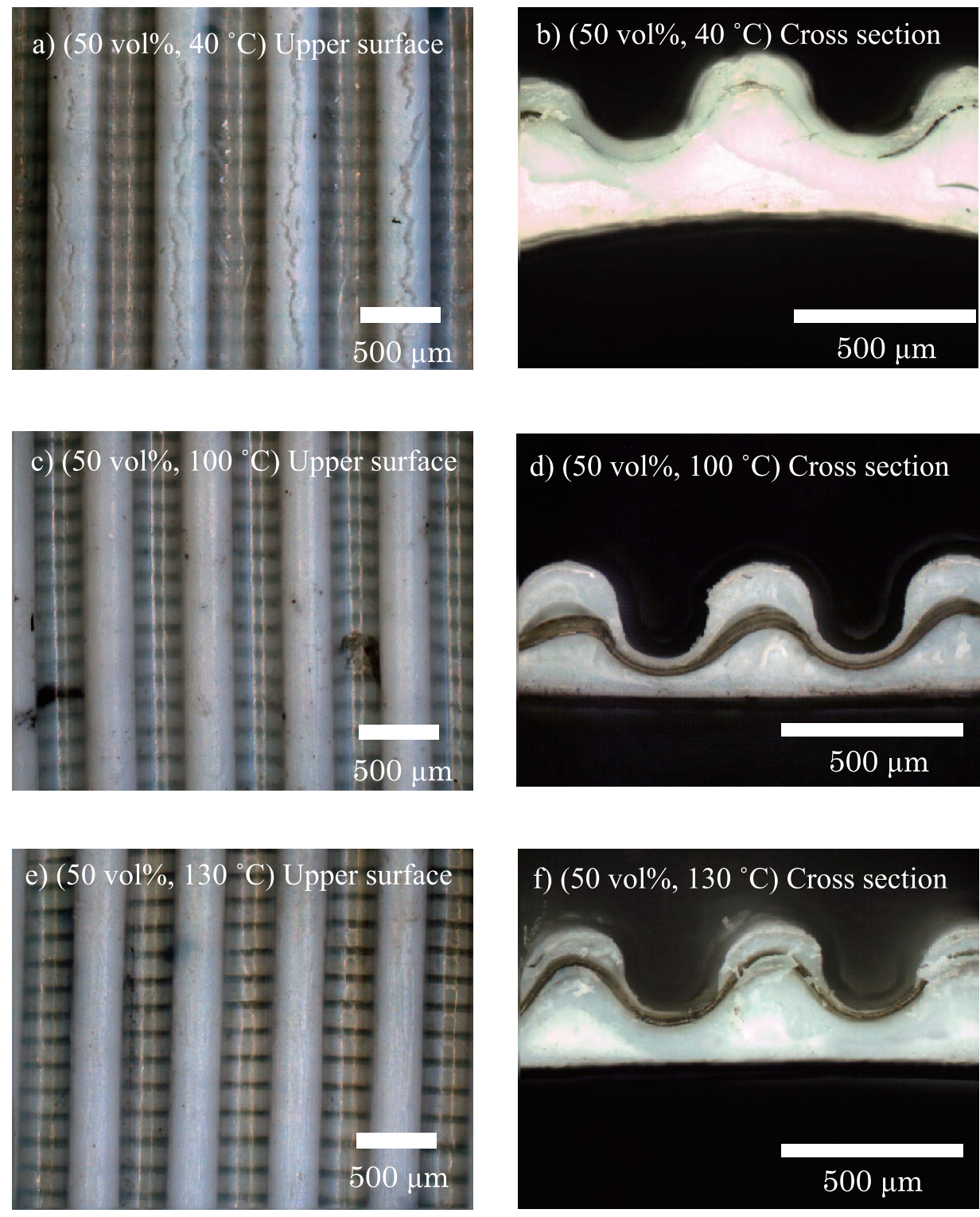

Fig. 10 Optical images of imprinted $50 \mathrm{vol} \%$ alumina compound sheet samples.

conditions. In these conditions, surface cracks were not found and the middle layer polyimide curved along the surface patterns.

\subsection{Debinding and sintering}

The CT (Computed Tomography) scanned image of sintered sample of $50 \mathrm{vol} \%$ alumina micro channels is shown in Fig. 12. Micro channels without defects were successfully formed. During the debinding process, the polymers in the alumina compound sheet decompose as gasses. These gases can cause inner pressure and lead to cracks in the structure. In our work, the heating program was controlled to allow polymers to decompose slowly. No fractures or cracks occur during the sintering process. The shrinkage rate of $50 \mathrm{vol} \%$ and 45 vol\% alumina compound sheets were $19 \%$ and $21 \%$, respectively. This indicates that shrinkage is reduced by including less polymers in the alumina compound sheets.

Micro channels formed by this method become a single ceramic structure. Due to this, the micro channels are strong against inner pressure. In addition, as these micro channels are not formed by laminating different materials, separation between upper and lower layer caused by difference in thermal expansion coefficient will not occur.

\section{Conclusion}

We propose a process to form alumina sheets with micro channels curving along surface patterns. By combining laser beam machining, imprinting with a deep mould, and a process of interposing sacrificial layers inside alumina compound sheets, we were successful in fabricating sound micro channels. These alumina micro channels can be applied as high-efficiency heat exchangers or Micro Electro Mechanical Systems used in harsh environments. By altering the laser beam machining program, shape of mould and stacking order of alumina compound sheets and laser beam machined layer, our microchannel forming process allows fabrication of complex outof-plane micro channels. 

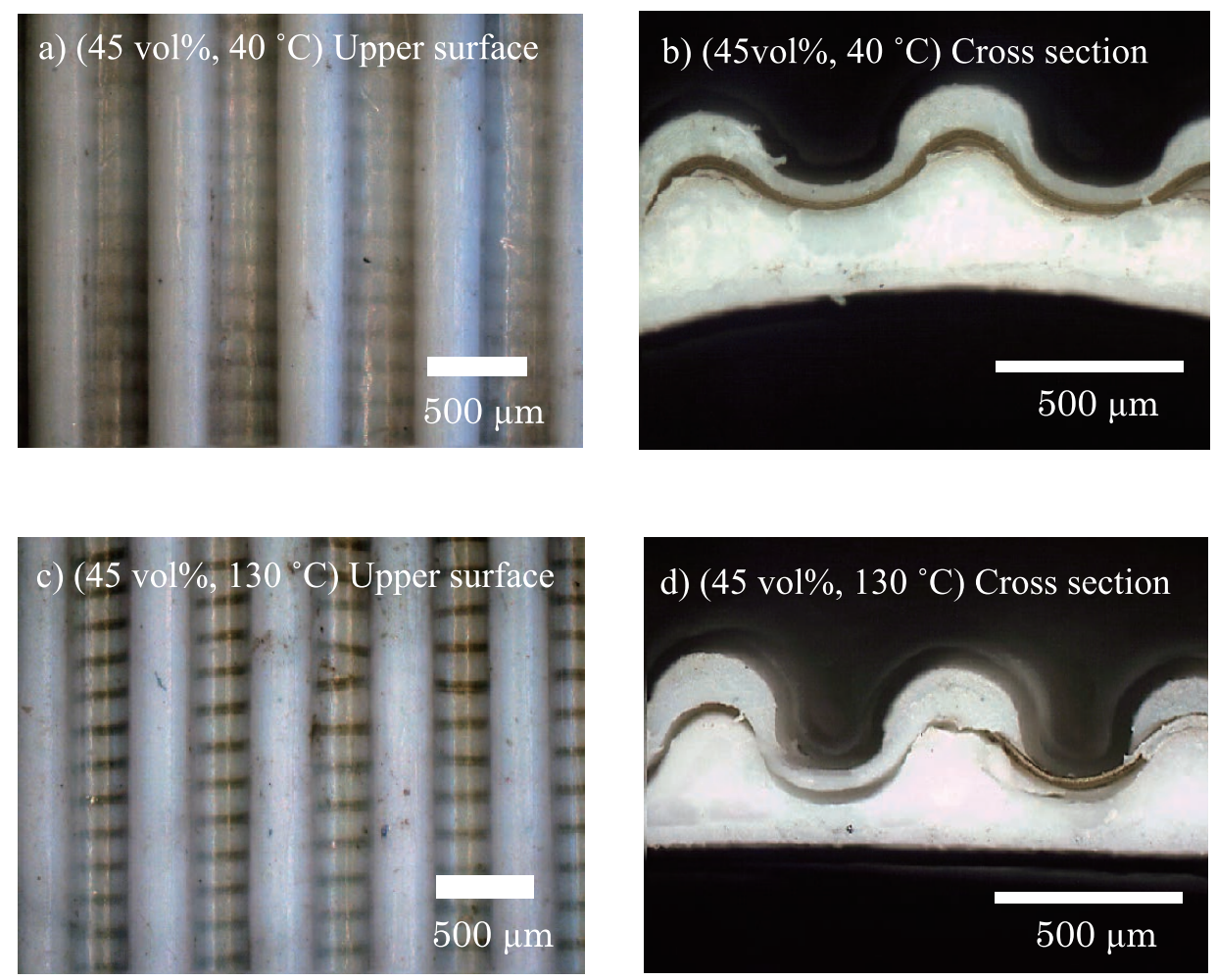

Fig. 11 Optical images of imprinted 45 vol\% alumina compound sheet samples.

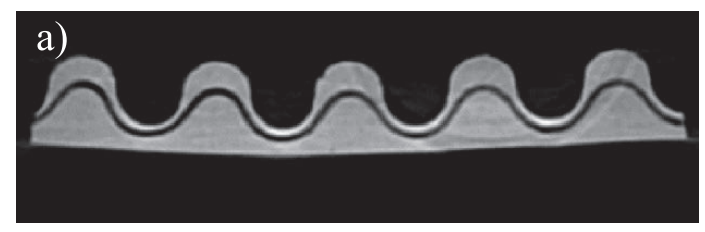

\section{References}

1) L. J. Guo, X. Cheng, C-F. Chou: "Fabrication of SizeControllable Nanofluidic Channels by Nanoimprinting and Its Application for DNA Stretching", Nano Letters, 4-1 (2004) 69-73.

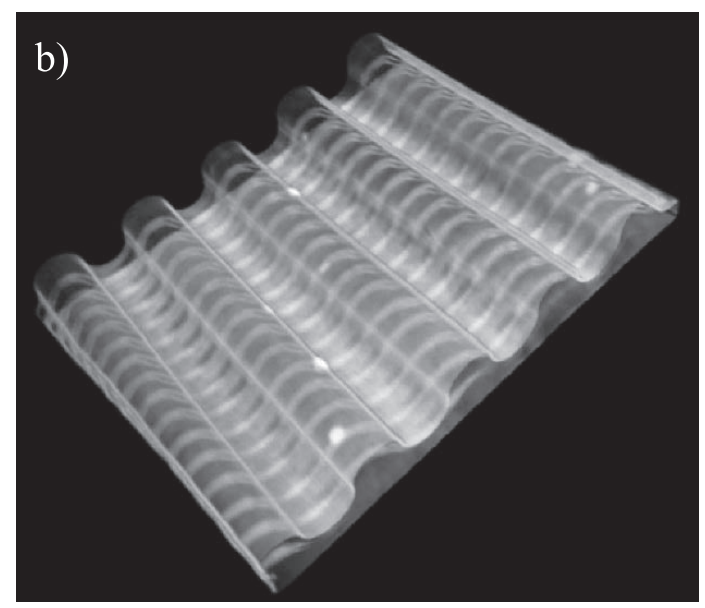

2) D. Xia, S. R. J. Brueck: "Fabrication of enclosed nanochannels using silica nanoparticles”, J. Vac. Sci. Technol, B 23 (2005) 2694-2699.

3) Y. Zhang, J. Lu, S. Shimano, H. Zhou, R. Maeda: "Development of MEMS-based direct methanol fuel cell with high power density using nanoimprint technology", Electrochem. Commun, 9 (2007) 1365-1368.

4) Q. Xia, K. J. Morton, R. H. Austin, S. Y. Chou: "Sub-10 nm Self-Enclosed Self-Limited Nanofluidic Channel Arrays", Nano Letters, 8-11 (2008) 3830-3833.

5) R. Yang, B-R. Lu, J. Wan, S-Q. Xie, Y. Chen, E. Huq, X-P. Qu, R. Liu: "Fabrication of micro/nano fluidic channels by nanoimprint lithography and bonding using SU-8", Microelectron. Engineering, 86(4) (2009) 1379-1381.

Fig. 12 CT scanned image of the alumina micro channels.

\section{Acknowledgements}

We would like to express our very great appreciation to Dr. Enomoto for his expertise and guidance during thermal analysis. The authors would also like to thank the following financial supports: JSPS KAKENHI Grant Number 15H04161, JST A-STEP program Grant Number AS262Z01235L, and The Amada Foundation.

6) Y. Xu, F. Tsumori, H. Kang, H. Miura: "Improvement of Solid Oxide Fuel Cell by Imprinted Micropatterns on Electrolyte", J. Jpn. Soc. Powder Powder Metallurgy, 58 (2011) 673-678.

7) Y. Xu, F. Tsumori, H. G. Kang, H. Miura: "Study on fabrication of micrometer patterned ceramic sheet with micro powder imprinting ( $\mu$ PI) method", Adv. Sci. Lett., 12(1) (2012) 170-173.

8) F. Tsumori, S. Hashimoto, M. Takahashi, Y. Xu, H. Kang, T. Osada, H. Miura: "Micrometer-scale Imprinting Process 
for Ceramic Sheet from Powder Compound Material", 11th International Conference on Technology of Plasticity, ICTP, (2014) 19-24.

9) Y. Xu, F. Tsumori, T. Osada, H. Miura: "Improvement of solid oxide fuel cell by imprinted micropatterns on electrolyte", Micro Nano Lett., 8 (2013) 571-574.

10) Y. Xu, F. Tsumori, S. Hashimoto, M. Takahashi, H. Kang, T. Osada, H. Miura: "Improvement of solid oxide fuel cell by imprinted patterns on electrolyte”, Proc. IEEE- Nano/Micro Engineered and Molecular Systems, (2013) 887-889.

11) F. Tsumori, Y. Tanaka, Y. Xu, T. Osada, H. Miura: "Development of improved solid oxide fuel cell electrolyte sheet by microimprinting for layered material”, Jpn. J. Appl. Phys., 53 (2014) 06JK02-1-06JK02-6.

12) F. Tsumori, Y. Xu, Y. Tanaka, T. Osada, H. Miura: "Micrometer-scale Imprinting Process for Ceramic Sheet from Powder Compound Material”, Procedia Eng., 81 (2014) 14331438.

13) F. Tsumori, L. Shen, Y. Xu, T. Osada, H. Miura: "Hierarchical patterning by multi-step micro imprinting with layered material”, Manufacturing Review, 2 (2015) 10.

14) A. Konno, H. Iwai, K. Inuyama, A. Kuroyanagi, M. Saito, H. Yoshida, K. Kodani, K. Toshikata: "Mesoscale-structure control at anode/electrolyte interface in solid oxide fuel cell", J. Power Sources, 196 (2011) 98-109.

15) H. Iwai, A. Kuroyanagi, M. Saito, A. Konno, H. Yoshida, T. Yamada, S. Nishiwaki: "Power generation enhancement of solid oxide fuel cell by cathode-electrolyte interface modification in mesoscale assisted by level set-based optimization calculation"
J. Power Sources, 196 (2011) 3485-3495.

16) A. Konno, H. Iwai, M. Saito, H. Yoshida: “A corrugated mesoscale structure on electrode-electrolyte interface for enhancing cell performance in anode-supported SOFC" J. Power Sources, 196 (2011) 7442-7449.

17) A. Konno, H. Iwai, M. Saito, H. Yoshida: "Effect of characteristic lengths of electron, ion, and gas diffusion on electrode performance and electrochemical reaction area in a solid oxide fuel cell”, Heat Transfer-Asian Res., 41 (2012) 700-718.

18) S. Y. Chou, P. R. Krauss, W. L. Guo, L. Zhuang: "Sub-10 nm imprint lithography and applications", Journal of Vacuum Science and Technology B: Microelectronics and Nanometer Structures, 15 (1997) 2897-2904.

19) S. Y. Chou, P. R. Krauss, P. J. Renstrom: "Imprint of sub$25 \mathrm{~nm}$ vias and trenches in polymers", Appl. Phys. Lett., 67 (1995) 3114-3116.

20) S. Y. Chou, P. R. Krauss, P. J. Renstrom: "25-nanometer resolution", Science, 272 (1996) 85-87.

21) B. G. Casey, W. Monaghan, C. D. W. Wilkinson: "Embossing of nanoscale features and environment", Microelectron. Eng., 35 (1997) 393-396.

22) S. Y. Chou, P. R. Krauss, P. J. Renstrom: "Nanoimprint lithography”, J. Vac. Sci. Technol., B14 (1996) 4129-4133.

23) F. Tsumori, S. Hunt, T. Osada, H. Miura: "Formation of ceramic micro-channel by combination of laser beam machining and micro powder imprinting”, Japan Society of Appl. Phys., 54 (2015) 06FM03-1- 06FM03-5. 